\title{
Investigation of Preschool Children's Descriptions of Value Concepts: A Qualitative Study
}

\author{
Nihat Topaç ${ }^{1}$, Musa Bardak ${ }^{1}$, Murat Kirişci ${ }^{1}$, and Ercan MERTOĞLU ${ }^{1}$ \\ ${ }^{1}$ Affiliation not available
}

December 22, 2020

\begin{abstract}
This study was conducted to investigate how early childhood children perceive and define various concepts of value. Phenomenology, which is one of the qualitative research patterns, was used in the study. The study group of the study consisted of 20 5-year-old children who continue preschool education. While determining the children, a typical case sampling, which is one of the purposeful sampling methods, was used. It was noted that the entire sample was not educated in the same socio-economic level and planned value education before. A data collection tool that consist of open-ended questions with 7 value concepts (responsibility, sharing, benevolence, friendship, respect, honesty and courtesy), selected by researchers, was applied to the children with a semi-structured interview technique. The data obtained were evaluated by content analysis method. The data obtained from the answers given by the participants to the questions about value concepts were coded and themes were created and arranged in tables. In the results obtained by defining and interpreting the findings, it was seen that the perceptions and definitions of children of responsibility, sharing, benevolence and respect values are similar. In defining the value of responsibility, children often try to make definitions over the tasks that are assigned to them at home; in the definitions of sharing and benevolence values, they were influenced by the experiences of sharing and solidarity they had previously experienced; In their definitions of respect value, it is seen that they are affected by the behaviors and teachings of adults around them. As a result of the research, the answers given by the children to the questions about the value concepts were grouped. It has been observed that the perceptions and definitions of children about responsibility, sharing, benevolence and respect values are similar. It was seen that they tried to explain the value of friendship through sharing and benevolence values. It has been found that the concepts of honesty and kindness are the least perceived and undefined ones.
\end{abstract}

\section{Hosted file}

de \selectlanguage\{polish\} $\breve{g} \backslash$ selectlanguage\{english\}erler makalesi.pdf available at https: //authorea.com/users/374526/articles/493388-investigation-of-preschool-children-sdescriptions-of-value-concepts-a-qualitative-study 